\title{
abLIM1 constructs non-erythroid cortical actin networks to prevent mechanical tension-induced blebbing
}

\author{
Guoqing $\mathrm{Li}^{1}$, Shan Huang${ }^{1}$, Sen Yang${ }^{1}$, Jiabin Wang${ }^{2}$, Jingli Cao ${ }^{1}$, Daniel M. Czajkowsky ${ }^{3}$, Zhifeng Shao ${ }^{3}$ and \\ Xueliang Zhu (1)
}

\begin{abstract}
The cell cortex is a layer of cytoskeletal networks underneath the plasma membrane, formed by filamentous actin (Factin) and cortex proteins including spectrin, adducin, and myosin. It provides cells with proper stiffness, elasticity, and surface tension to allow morphogenesis, division, and migration. Although its architecture and formation have been widely studied in red blood cells, they are poorly understood in non-erythrocytes due to structural complexity and versatile functions. In this study, we identify the actin-binding protein abLIM1 as a novel non-erythroid cell-specific cortex organizer. Endogenous abLIM1 colocalized with cortical $\beta$ II spectrin but upon overexpression redistributed to thick cortical actin bundles. abLIM1 associated with major cortex proteins such as spectrins and adducin in vivo. Depletion of abLIM1 by RNAi induced prominent blebbing during membrane protrusions of spreading or migrating RPE1 cells and impaired migration efficiency. Reducing cortical tensions by culturing the cells to confluency or inhibiting myosin activity repressed the blebbing phenotype. abLIM1-depleted RPE1 or U2OS cells lacked the dense interwoven cortical actin meshwork observed in control cells but were abundant in long cortical actin bundles along the long axis of the cells. In-vitro assays indicated that abLIM1 was able to crosslink and bundle F-actin to induce dense F-actin network formation. Therefore, abLIM1 governs the formation of dense interconnected cortical actin meshwork in non-erythroid cells to prevent mechanical tension-induced blebbing during cellular activities such as spreading and migration.
\end{abstract}

\section{Introduction}

The cell cortex is a thin layer of actin network underneath and anchored to the plasma membrane, ranging from $50 \mathrm{~nm}$ to $2 \mu \mathrm{m}$ in thickness. It is important for shape, division, migration, and morphogenesis of animal cells. It also modulates membrane microdomains and

Correspondence: Xueliang Zhu (xlzhu@sibcb.ac.cn)

'State Key Laboratory of Cell Biology, CAS Center for Excellence in Molecular Cell Science, Shanghai Institute of Biochemistry and Cell Biology, Chinese

Academy of Sciences, University of Chinese Academy of Sciences, 320 Yueyang Road, Shanghai 200031, China

${ }^{2}$ Shanghai Center for Systems Biomedicine, Key Laboratory of Systems Biomedicine (Ministry of Education), Shanghai Jiao Tong University, 800

Dongchuan Road, Shanghai 200240, China

Full list of author information is available at the end of the article.

These authors contributed equally: Guoqing Li, Shan Huang contributes to transmembrane processes such as endocytosis and exocytosis ${ }^{1-8}$.

The most studied cell cortex is that of red blood cells. The erythroid cortex is a polygonal meshwork composed of $\alpha \mathrm{I}$ and $\beta \mathrm{I}$ spectrin tetramers cross-linked at nodes by short filamentous actin (F-actin) and other cortex proteins such as adducin, ankyrin, dematin, and tropomyo$\sin ^{5,7,9}$. It is pinned to the plasma membrane through associations with phosphatidylinositol lipids and transmembrane proteins ${ }^{7,9}$. Mutations in the cortex proteins cause defected erythroid morphology and function?

By contrast, non-erythroid cortexes are mostly irregular and dynamic in structure and are mainly composed of Factin networks ${ }^{10-13}$. Only neurons have recently been found to contain ordered cortical actin structures along

\section{(c) The Author(s) 2018}

(c) (i) Open Access This article is licensed under a Creative Commons Attribution 4.0 International License, which permits use, sharing, adaptation, distribution and reproduction cc) in any medium or format, as long as you give appropriate credit to the original author(s) and the source, provide a link to the Creative Commons license, and indicate if changes were made. The images or other third party material in this article are included in the article's Creative Commons license, unless indicated otherwise in a credit line to the material. If material is not included in the article's Creative Commons license and your intended use is not permitted by statutory regulation or exceeds the permitted use, you will need to obtain permission directly from the copyright holder. To view a copy of this license, visit http://creativecommons.org/licenses/by/4.0/. 


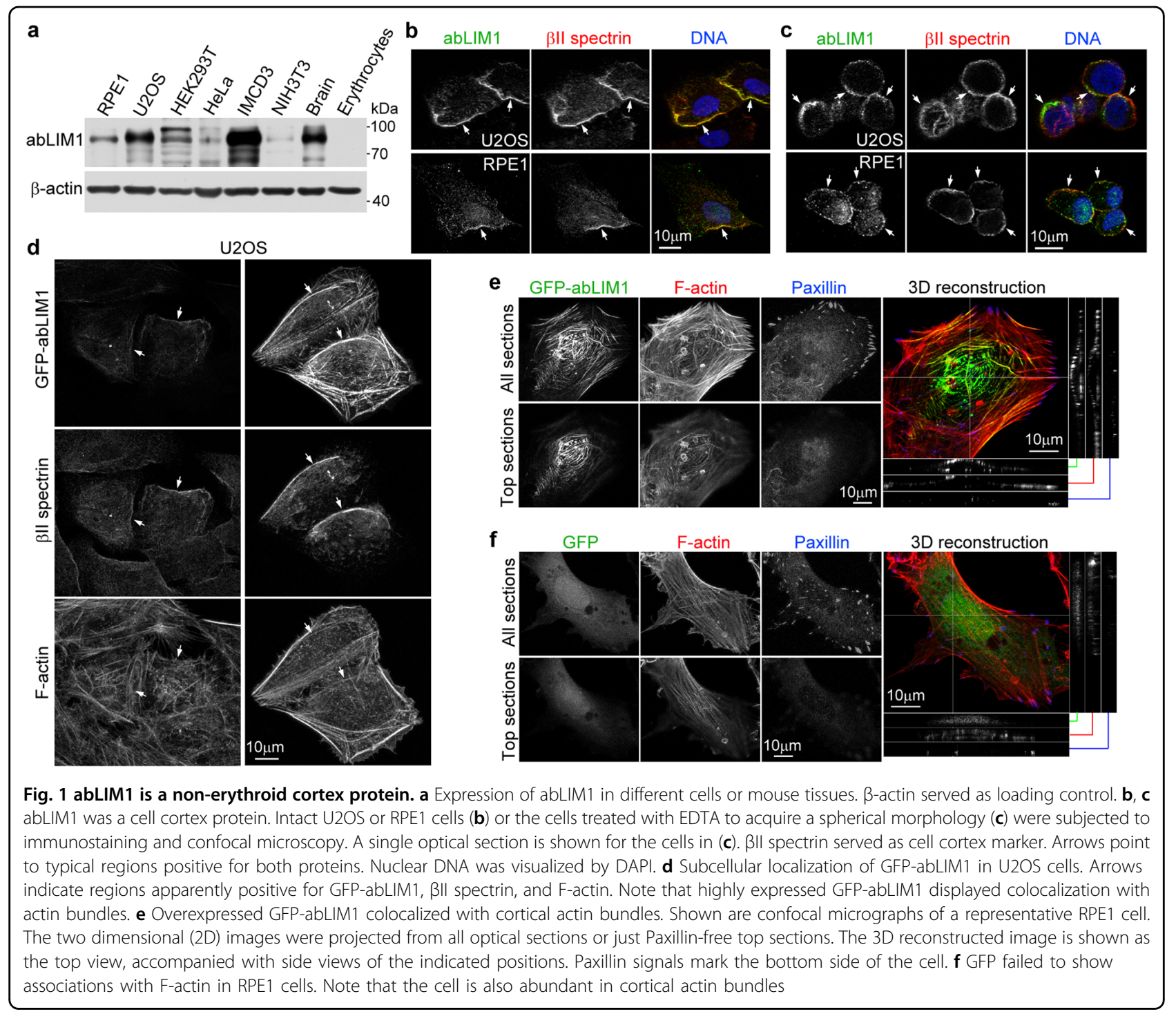

their neurites, in which short actin filaments are proposed to form rings of 180 to $190-\mathrm{nm}$ periodicity interspaced laterally by spectrin tetramers ${ }^{14-16}$. Although nonerythrocytes use different spectrin paralogs (such as $\alpha \mathrm{II}$ and $\beta$ II spectrins), they appear to share other cortical cytoskeleton components with erythrocytes ${ }^{5,7,9,14}$. How a similar set of cortical proteins can organize such diverse cytoskeletal networks in different cellular context is not known. One possibility is that unidentified actin regulators contribute to the construction of the nonerythroid cortexes. This, however, is not documented to date.

Vertebrate abLIM1-3 are poorly studied actin-binding proteins. Their $\mathrm{N}$-terminal halves contain four zincbinding LIM domains, whereas their C-terminal halves are entirely homologous to dematin (see Supplementary Fig. 1$)^{17-21}$. abLIM1-3 appear to show both overlapping and distinct expressing patterns in different tissues or cells $^{17,20,21}$. abLIM1 and abLIM2 localize to the lateral boundary of the sarcomere, or the z-discs, of striated muscles ${ }^{17,20,22}$. Consistent with their actin-binding properties, the abLIM proteins display stress fiber-like localizations upon overexpression and are important for cell migration ${ }^{17}$ 20, 23 . Furthermore, depletion of abLIM1 reduces the number of stress fibers in NIH3T3 cells, whereas its overexpression increases cellular F-actin ${ }^{24,} 25$.

We have previously found that depletion of abLIM1 or abLIM3 by RNAi markedly promotes ciliogenesis in the presence of serum in cultured cells by influencing actin dynamics $^{23}$. In this report, we identify abLIM1 as a novel component of the non-erythroid cortex that is critical for the formation of cortical F-actin networks and proper plasma membrane-cell cortex attachment under mechanical tension. 


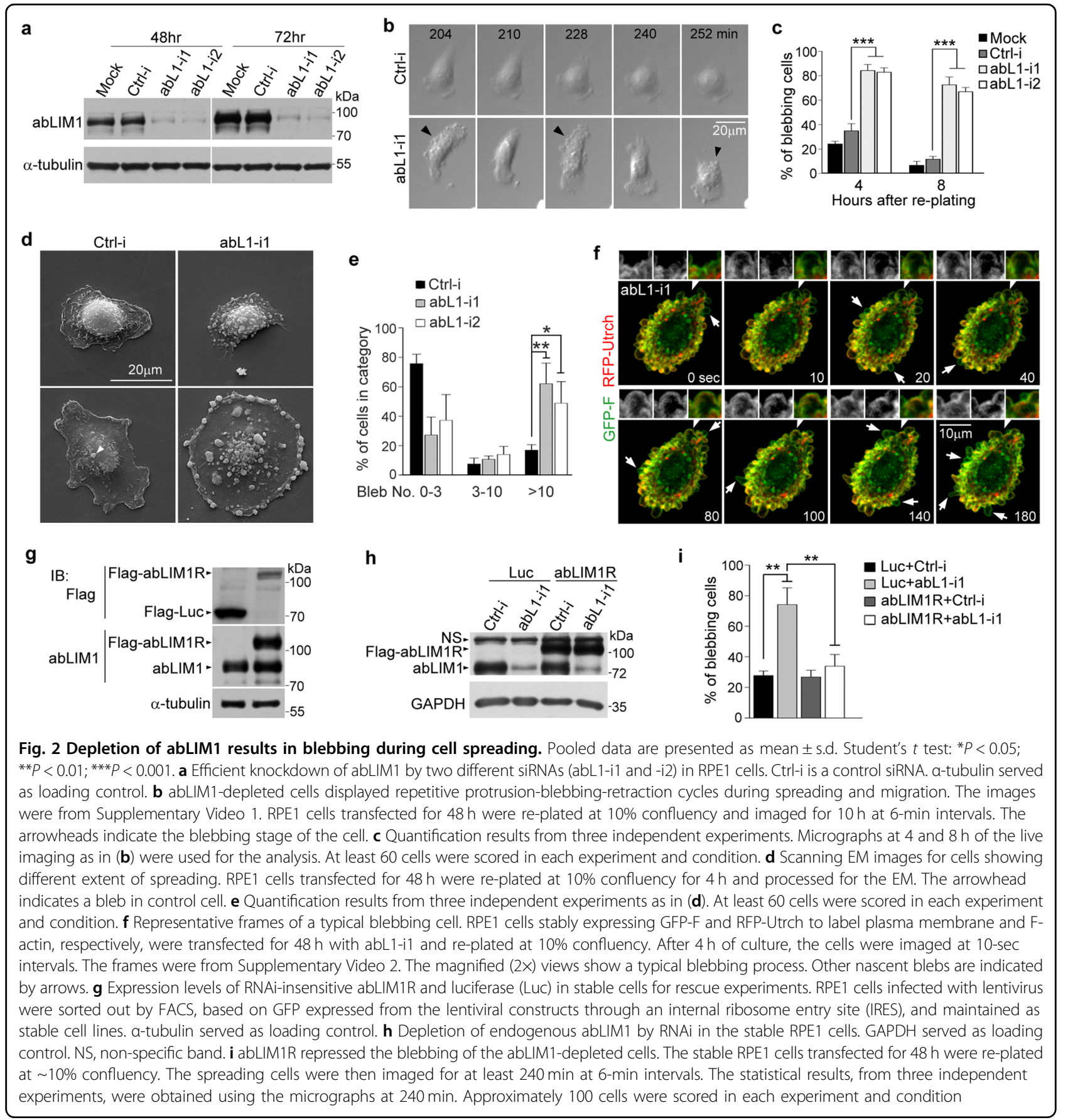

\section{Results}

\section{abLIM1 is a non-erythroid cortex protein}

abLIM1 showed varying expression levels in cultured cells and mouse tissues but was undetectable in red blood cells (Fig. 1a) ${ }^{17}$. Immunostaining revealed that it was highly enriched at cell edges in RPE1 and U2OS cells, where its immunofluorescent signals colocalized with those of $\beta$ II spectrin (Fig. 1b), a cell cortex marker, ${ }^{5}$. To validate the antibody specificity, we pre-incubated the anti-abLIM1 antibody with purified polyhistidine (His)- tagged human abLIM1, abLIM3, or GFP and found that only the pre-incubation with His-abLIM1 abolished the cortical immunofluorescent signals (Supplementary Fig. 2a,b). Depletion of abLIM1 using abL1-i1, a previously described siRNA ${ }^{23}$, also abolished the signals (Supplementary Fig. 2c,d). Furthermore, when the cells were partially detached from the substratum to become roundup, abLIM1 was seen clearly at the cortex, being more punctate than $\beta$ II spectrin (Fig. 1c). Thus, abLIM1 is a cell cortex protein specifically in non-erythrocytes. 
Interestingly, upon overexpression abLIM1-3 exhibit prominent colocalization with actin bundles ${ }^{20,} 23$. We found that exogenous abLIM1 at low expression levels tended to assume endogenous abLIM1-like distributions but at high expression levels expanded to actin bundles in addition to the colocalization with $\beta$ II spectrin (Fig. 1d and Supplementary Fig. 2e). To clarify the identity of these bundles, we used paxillin, a focal adhesion protein, to mark the bottom side of the cells ${ }^{26,27}$ and analyzed $\mathrm{z}$ stack images of GFP-abLIM1-expressing RPE1 cells. We found that a portion of the F-actin bundles and their associated GFP-abLIM1 were actually distributed along the top surface of the cells (Fig. 1e), indicating that they belong to cortical actin. Such cortical F-actin bundles also existed in intact cells or cells overexpressing GFP (Fig. 1f). Therefore, abLIM1 is absent in spectrin-free cortical actin bundles unless being overexpressed.

\section{Depletion of abLIM1 results in blebbing during cell spreading}

To understand whether abLIM1 has a role in the cortical actin network, we depleted abLIM1 in RPE1 cells (Fig. 2a) and examined spreading behaviors of the cells after re-plating. Compared to control cells that were either mock-transfected or transfected with a control siRNA, ctrl-i ${ }^{23}$, those transfected with abL1-i1 or abL1-i2 tended to manifest numerous tiny and dynamic puffs all over the cells (Fig. 2b,c and Supplementary Video 1). Some of the puffs emerged from the cell edge (Fig. $2 \mathrm{~b}$ and Supplementary Video 1), suggesting that they are membrane blebs ${ }^{4,28,29}$. We found that massive blebs suddenly broke out during cell protrusion, resulting in premature retraction of the leading edge, during which process the blebs gradually reduced in number or even vanished. Accordingly, the cells underwent repetitive spreadingblebbing-retraction cycles. Control cells, however, displayed much less extent of blebbing (Fig. 2b, c and Supplementary Video 1). Scanning electron microscopy (EM) revealed that the cells treated with abL1-i1 or -i2 were abundant in membrane blebs of varying sizes (Fig. 2d, e). $49 \pm 15 \%$ or more of the cells contained $>10$ blebs of varying sizes per cell. By contrast, the value was $17 \pm 4 \%$ in the ctrl-i treated populations (Fig. 2d, e). When GFP-F and RFP-Utrch were stably expressed to simultaneously label the plasma membrane and F-actin, respectively (Fig. 2f and Supplementary Fig. 3) ${ }^{30-32}$, the cells treated with abL1-i1 displayed typical blebbing behaviors. Initially a patch of plasma membrane free of RFP-Utrch rapidly puffed up. F-actin, as indicated by RFP-Utrch, was then progressively assembled at the membrane domain as the blebs grew. After reaching the maximal RFP-Utrch intensity, the blebs started to retract (Fig. $2 \mathrm{f}$ and Supplementary Video 2$)^{4,12}$. Thus the depletion of abLIM1 leads to membrane blebbing during cell spreading.
To rule out the off-target effect of the RNAi experiments, we created an RNAi-resistant isoform of abLIM1 (hereafter termed abLIM1R) by mutating the target sequence of abL1-i1 without altering the coding amino acids. We established an RPE1 cell line stably expressing Flag-HA-abLIM1R to levels close to those of the endogenous abLIM1 (Fig. 2g). Depleting endogenous abLIM1 from the stable RPE1 cells by RNAi no longer triggered blebbing during cell spreading (Fig. 2h, i). By contrast, the RNAi-induced blebbing was still prominent in RPE1 cells stably expressing Flag-HA-luciferase (Fig. 2g-i). abL1-i1 is thus specific to abLIM1.

\section{Depletion of abLIM1 impairs cell migration efficiency by causing blebbing}

We have previously shown that abLIM1 is required for efficient directional cell migration in wound healing assays $^{23}$. As cell migration also involves membrane protrusion, we examined migrating behaviors of abLIM1depleted RPE1 cells. To avoid influences of neighboring cells, we seeded the cells sparsely for at least $12 \mathrm{~h}$ and monitored their free migrations through live imaging. We found that, similar to the spreading cells (Fig. 2b, c), these migrating cells also displayed spreading-blebbingretraction cycles: blebbing emerged all over the cells during plasma membrane protrusions, followed by membrane retraction (Fig. 3a, b and Supplementary Video 3). Accordingly, the cells tended to oscillate around their initial positions and exhibit poor migration efficiency (Fig. 3a and Supplementary Video 3). When the net displacement in $10 \mathrm{~h}$ was measured to reflect the ability of directional migration, the median for the control cells was $55.1 \mu \mathrm{m}$ (Fig. 3c). By contrast, the value was only 23.8 and $23.2 \mu \mathrm{m}$ for the cells treated with abL1-i1 or abL1-i2, respectively (Fig. 3c).

To exclude off-target effect, we transfected the stable RPE1 cells expressing Flag-HA-abLIM1R or -luciferase with ctrl-i or abL1-i1 (Fig. 2g, h) and examined their migration abilities. Upon the depletion of the endogenous abLIM1, the cells expressing abLIM1R indeed displayed markedly increased net displacements as compared to those expressing luciferase (Fig. 3d). Therefore, abLIM1depleted cells lack persistent directionality in free migration due to protrusion-induced blebbing.

\section{abLIM1-induced cortical actin antagonizes mechanical tension-induced blebbing}

To clarify whether the blebbing of abLIM1-depleted cells was due to mechanical tension, we examined confluent RPE1 cells, which lack the membrane protrusioninduced tension. Indeed, blebbing was no longer observed in confluent cells upon abLIM1 depletion when examined by live imaging (Fig. 4a, b). 


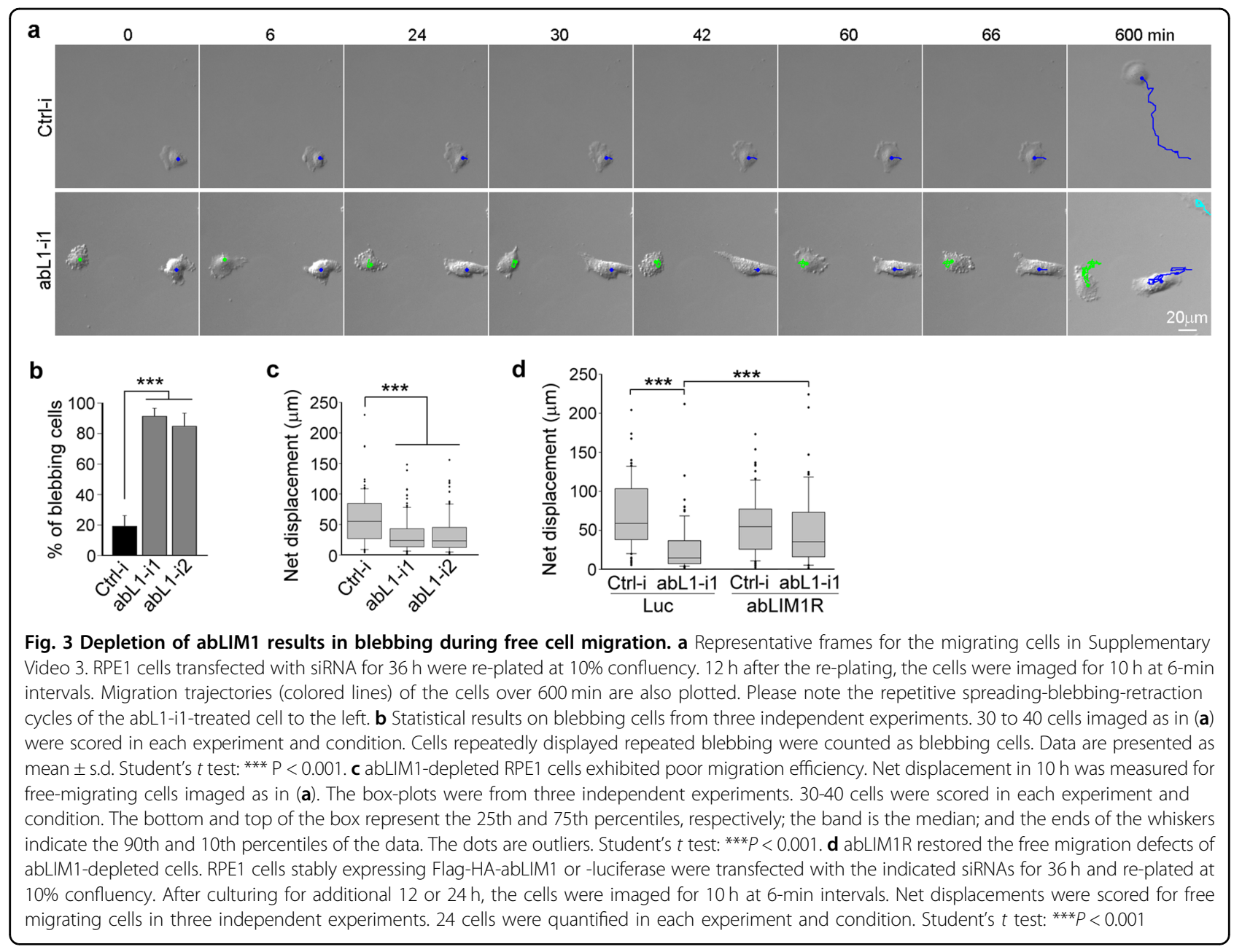

As repressing myosin II activity can reduce cortical tension and subsequently repress tension-induced bleb formation $^{29,33,34}$, we treated abLIM1-depleted RPE1 cells with blebbistatin, a myosin II inhibitor, or Y27632, which inhibits the myosin II-activator Rho-associated protein kinase (ROCK) ${ }^{29}$. Immediately following the addition of the drugs, the blebbing effect of the abLIM1-depleted RPE1 cells was markedly suppressed (Fig. 4c, d). The depletion of abLIM1, however, did not augment myosin II activities when the phosphorylation levels of myosin light chain 2 (MLC2, also called RLC) ${ }^{35,} 36$ were assessed (Supplementary Fig. 4). Phosphorylation levels of the ezrin, radixin, and moesin proteins (ERMs), important anchors of cortical actin to the plasma membrane ${ }^{37}$, were grossly unaffected as well (Supplementary Fig. 4). Taken together, we conclude that the cortical actin networks assembled by abLIM1 function to counteract mechanical tension during cellular activities such as membrane protrusion.
abLIM1 is essential for the formation of dense interwoven cortical meshwork

To understand why the abLIM1-depleted cells are prone to blebbing, we visualized cortical actin with scanning EM. We treated RPE1 cells transfected with ctrli or abL1-i1 for $48 \mathrm{~h}$ with $1 \%$ Triton X-100 to remove plasma membranes and soluble biomolecules prior to fixation, as described previously ${ }^{38}$. The control RPE1 cells mostly displayed a dense cortical meshwork of interwoven filaments and their bundles (Fig. 5a, b). By contrast, the majority of abLIM1-depleted cells contained sparse cortical actin filaments (Fig. 5a, b). Concomitantly, bundles along the long axis of the cells became prominent (Fig. 5a).

To corroborate the EM results, we performed atomic force microscopy (AFM) to directly image the cortex in living cells ${ }^{39}$. As RPE1 cells often did not hold tightly enough on the substratum during the tip-scan imaging, we used U2OS cells instead (Fig. 5c). In the control cells, 


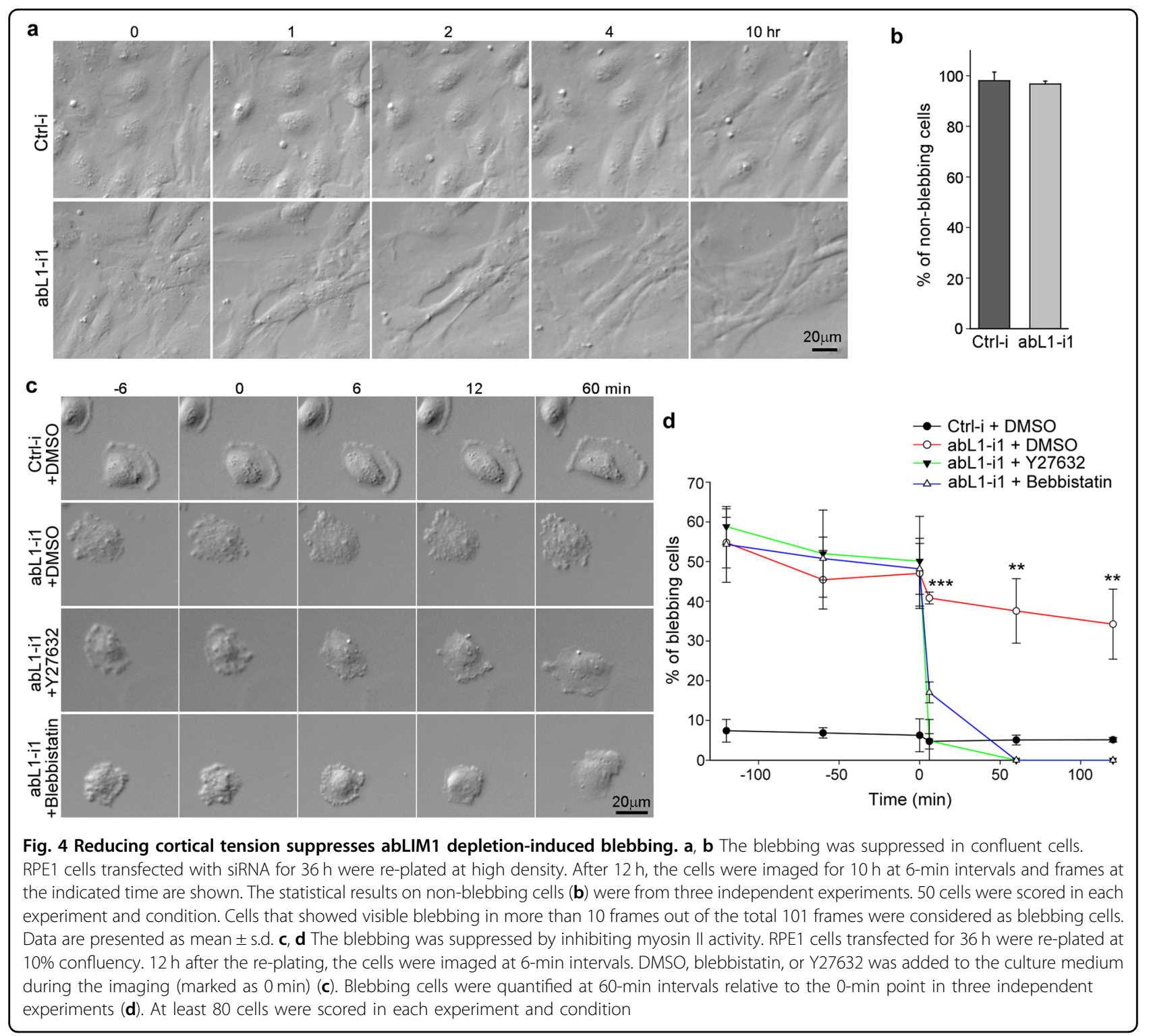

thick cortical fibers were found to branch hierarchically into numerous thinner interconnecting fibers to form intricate networks (Fig. 5d). By sharp contrast, the abLIM1-depleted cells were only abundant in arrays of thick fibers along the long axis. High resolution scan revealed that these cells clearly lacked the intricate fiber structures observed in the control cells (Fig. 5d). Accordingly, cortical stiffness in the abLIM1-depleted cells increased by $60 \%$ at nuclear regions and $151 \%$ at perinuclear regions as compared to the control cells (Fig. 5e).

To clarify whether the depletion of abLIM1 affected the thickness of cortical actin, we treated U2OS cells with EDTA to allow them to round up and acquired images by Stimulated Emission Depletion (STED) microscopy (Supplementary Fig. 5a), which can achieve a resolution higher than $100 \mathrm{~nm}$ at the $\mathrm{x}-\mathrm{y}$ plane ${ }^{40}$. Cortical actin thickness was measured as $214.0 \pm 15.6 \mathrm{~nm}$ for control cells and $216.4 \pm 17.9 \mathrm{~nm}$ for abLIM1-depleted cells (Supplementary Fig. 5b, c).

Taken together, we conclude that depletion of abLIM1 altered structural organization of cortical actin by impairing its interwoven meshwork but enhancing thick long fibers.

\section{abLIM1 crosslinks and bundles F-actin into dense meshwork in vitro}

Next we examined how abLIM1 could affect F-actin through in vitro assays. Full-length abLIM1 has been documented to be prone to degradation when expressed in E. coli but a short isoform (abLIM-s) containing only the dematin-homologous region can be expressed and 


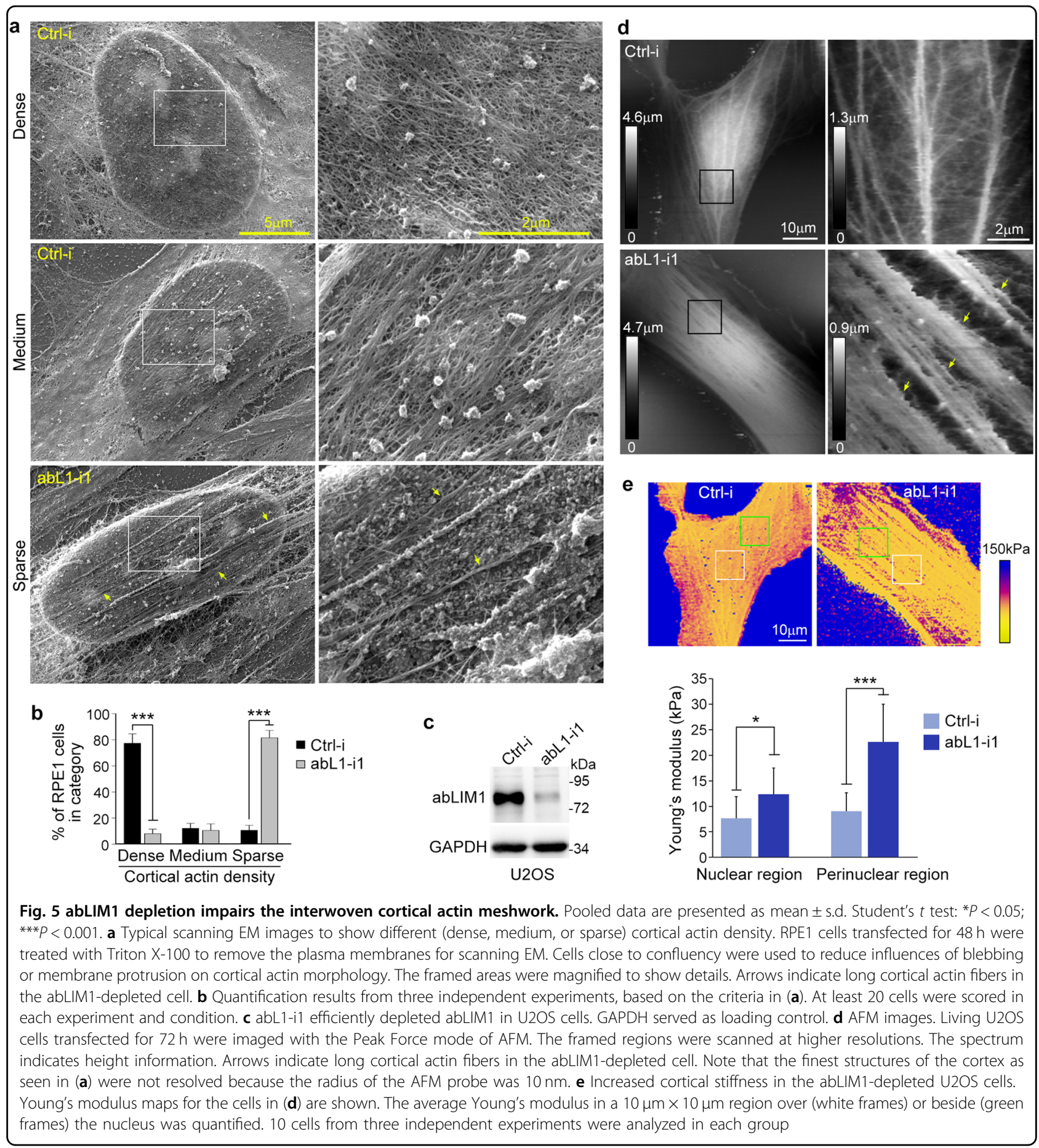

shown to co-sediment with F-actin ${ }^{17}$. We expressed His or GST-tagged abLIM1 in E. coli but found that it existed solely in inclusion bodies. We thus created two mutants, one equivalent to abLIM-s (namely herein $\triangle$ LIM) and the other containing only the VHP domain (Fig. 6a; also see Supplementary Fig. 1), and purified His-GFP, His-GFP$\triangle$ LIM, and His-GFP-VHP from E. coli for in vitro assays (Fig. 6b).
When $3 \mu \mathrm{m}$ of the purified proteins were added into preformed F-actin (Fig. 6c), we found that His-GFP$\triangle$ LIM, but not His-GFP-VHP or His-GFP, distributed along actin filaments and potently induced intricate F-actin networks (Fig. 6d). Negative staining EM indicated that His-GFP- $\triangle$ LIM induced actin bundles and cross-linked them into networks (Fig. 6e). These results suggest that abLIM1 is a microfilament bundling and 


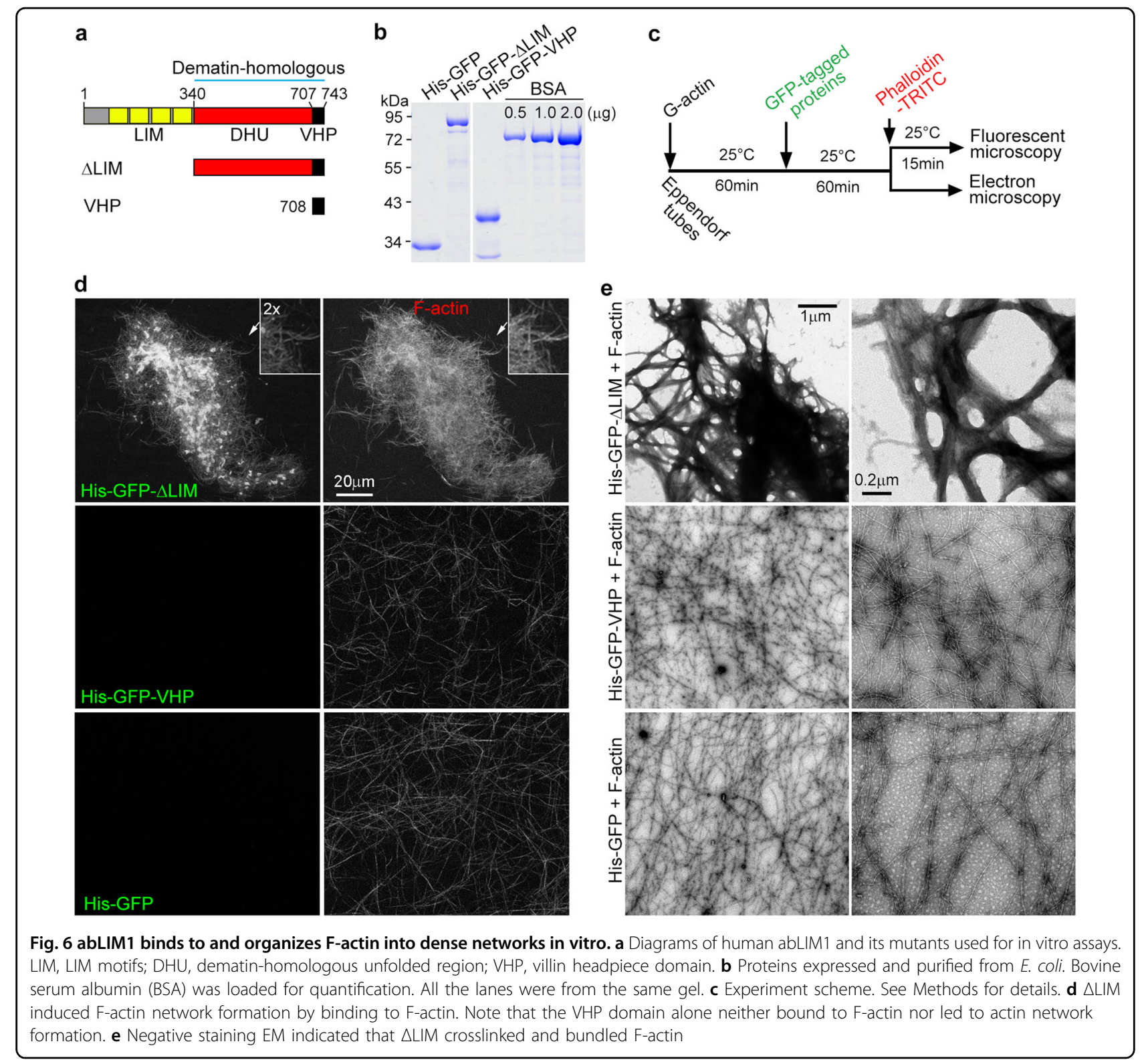

crosslinking protein capable of inducing F-actin network formation.

\section{abLIM1 associates with cell cortex proteins through its dematin-homologous region}

To understand how abLIM1 is targeted to the cortex, we performed co-immunoprecipitation (co-IP) by mixing Flag-abLIM1 or Flag-luciferase (a negative control) expressed in HEK293T cells with mouse brain lysates to identify its associated proteins, as done previously ${ }^{41}$. Silver staining indicated that many more proteins were associated with Flag-abLIM1 than with Flag-luciferase (Supplementary Fig. 6a). Subsequent shotgun mass spectrometry identified multiple cortex proteins such as $\alpha \mathrm{II}$ and $\beta$ II spectrins, $\alpha$ adducin, and ankyrin-2 (Supplementary Fig. $6 \mathrm{a})^{7}$. To confirm the mass spectrometric results, we expressed Flag- or GFP-tagged abLIM1 or its mutants (Fig. 7a) in HEK293T cells and performed co-IP with the cell lysates. Immunoblotting using available antibodies confirmed the associations of endogenous spectrins and adducin with abLIM1 (Fig. 7b, c). These cortex proteins associated with Flag- $\Delta$ LIM but not Flag- $\Delta$ VHP or GFPVHP (Fig. 7b, c), suggesting that the entire dematinhomologous region (equivalent to $\triangle \mathrm{LIM}$ ) is required for the associations. These cortex proteins readily displayed enhanced associations with Flag- $\Delta$ LIM but failed to associate with Flag- $\Delta$ VHP or GFP-VHP (Fig. 7b, c), suggesting that the entire dematin-homologous region 


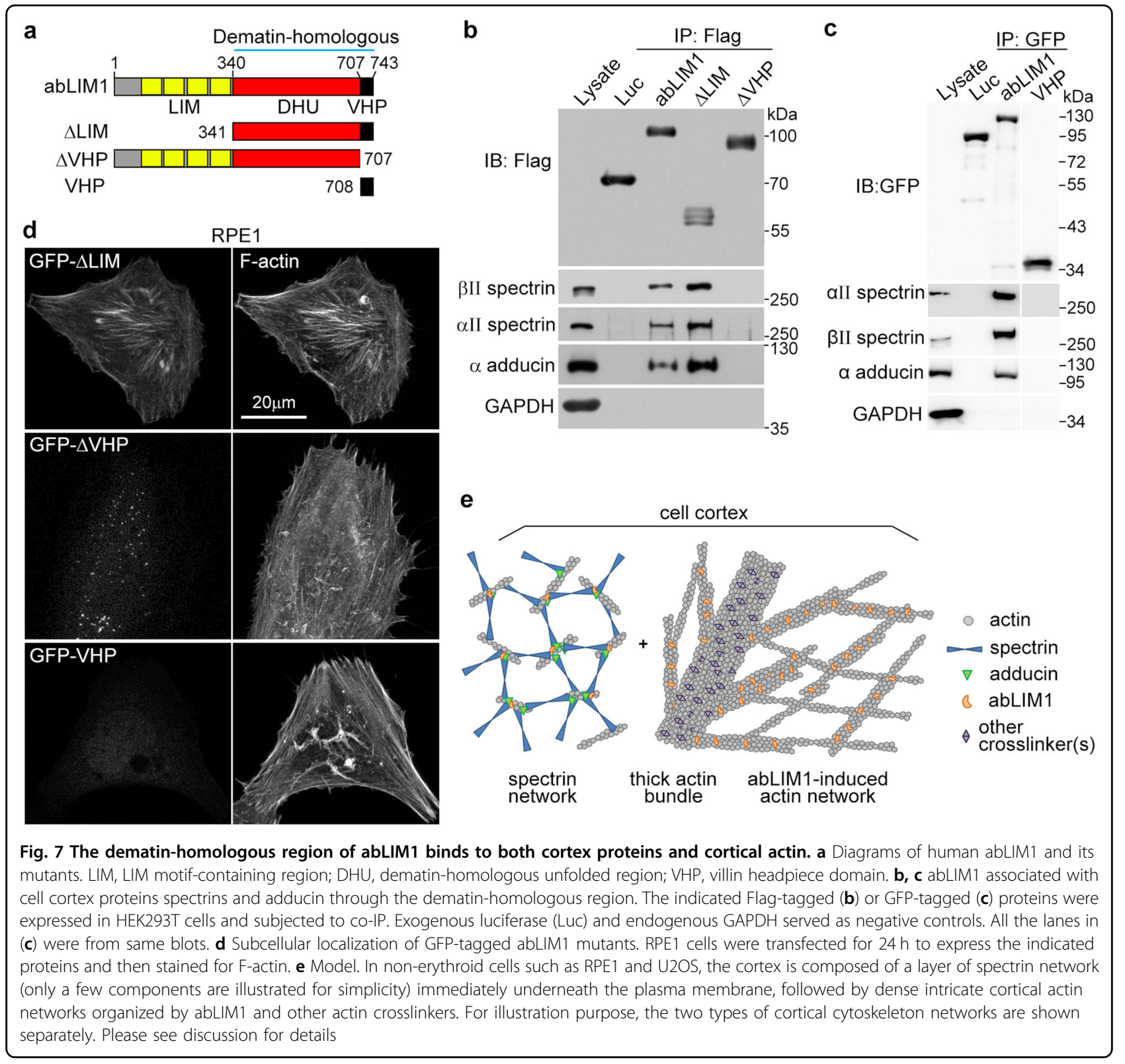

(equivalent to $\Delta$ LIM) is required for the associations but the $\mathrm{N}$-terminal LIM domain-containing region is inhibitory.

We then expressed these proteins as GFP fusions in RPE1 cells and examined their subcellular localizations. GFP- $\triangle$ LIM exhibited strong associations with bundled Factin (Fig. 7d), similar to the full-length GFP-abLIM1 (Fig. 1d, e). By contrast, GFP-tagged $\triangle$ VHP and VHP displayed neither F-actin association nor spectrin-like enrichment at cell edges (Fig. 7d). Thus, the dematinhomologous region is also required for the association of abLIM1 with cortical actin filaments.

Finally, we investigated whether the depletion of abLIM1 affected the cortex localization of spectrin. We imaged spherical U2OS cells, induced by the EDTA treatment, with a confocal microscope (Supplementary Fig. 6b) and quantified relative immunofluorescent intensities using single optical sections at approximately the equator of the cells (Supplementary Fig. 6c). The average intensities of abLIM1 and BII spectrin were reduced by $81.5 \%$ and $30.2 \%$, respectively, in the cells transfected with abL1-i1 as compared to the control cells (Supplementary Fig. 6c). Thus, abLIM1 also contributes to the cortical localization of spectrin.

\section{Discussion}

We demonstrated that abLIM1 is a non-erythrocytespecific cortex protein critical for the formation of dense 
interwoven cortical actin meshwork (Figs. 5 and 6). Such abLIM1-dependent actin networks antagonize cortical tensions generated by membrane protrusion, myosinmediated contraction, and possibly other mechanical stresses (Figs. 2-4) ${ }^{1,3}$. Accordingly, cells lacking abLIM1 displayed prominent blebbing during cell spreading or migration (Figs. 2-3). abLIM1 is widely expressed in cell lines and tissues (Fig. 1a) ${ }^{17}$ and may have similar functions in them. As overexpressed abLIM2 or abLIM3 also display colocalization with F-actin fibers $^{20,23}$, they may function similarly to abLIM1 in different cells or redundantly with abLIM1 in the same cells. Nevertheless, we found that abLIM1 is not required for the assembly and function of the cage-like cortical actin meshwork under the bleb membrane (Fig. 2f and Supplementary Video 2) ${ }^{12,} 42$.

abLIM1 may organize F-actin through similar mechanisms as dematin. An F-actin crosslinker must have two actin binding sites, achieved through either two intrinsic sites or dimerization when there is only one ${ }^{7,43 \text {, }}$ ${ }^{44}$. Dematin is known to contain two actin-binding sites, one in its N-terminal unfolded region and the other in the VHP domain ${ }^{45,}{ }^{46}$. We found that the entire dematinhomologous region of abLIM1, i.e., $\triangle$ LIM, also binds to and crosslinks F-actin into networks (Figs. 6 and 7d), suggesting that it contains two actin-binding sites as well. Nevertheless, unlike dematin, the VHP domain of abLIM1 alone does not show detectable binding to F-actin both in vitro and in vivo (Figs. 6 and 7d). The failure of $\triangle \mathrm{VHP}$, a mutant lacking only the VHP domain, to associate with F-actin in cells (Fig. 7a, d) suggests that the dematinhomologous unfolded region of abLIM1 alone (termed herein as the DHU region; Fig. 7a) is not sufficient for binding to F-actin, either. As VHP domains from different proteins can show diverse actin-binding activities in vitro ${ }^{47}$, our results imply that the VHP and DHU regions of abLIM1 may need to stay together to augment each other's actin binding activities so that $\triangle$ LIM can bind and crosslink F-actin. In addition, abLIM1 may be regulated by mechanisms distinct from dematin. For instance, the F-actin crosslinking activity of dematin is negatively regulated by protein kinase A-mediated phosphorylation of Ser381 in the VHP domain ${ }^{46,48,49}$. This site, however, is not conserved in abLIM proteins. On the other hand, DYRK1A kinase is reported to negatively regulate abLIM1 $1^{24,25}$.

Our results suggest that abLIM1 is recruited to the cortical spectrin network through association with spectrins and/or spectrin-associated proteins such as adducin (Fig. 7 and Supplementary Fig. 6a). In red blood cells the cortex is mainly formed by $\alpha \mathrm{I}$ and $\beta \mathrm{I}$ spectrin tetramers, crosslinked by short actin filaments and associated cortical actin-binding proteins such as adducin and dematin, and anchored to the plasma membrane through other cortex components such as ankyrin ${ }^{5,7}, 9$. Dematin is located at the junction of the spectrin tetramer and Factin and can facilitate the spectrin-actin interactions ${ }^{5,49}$. Dematin deficiency in mice reduced erythroid membraneassociated spectrin and adducin and caused extensive bleb formation in erythrocytes and severe anemia ${ }^{50}$. Similarly, in non-erythroid cells we found that depletion of abLIM1 by RNAi led to bleb formation and reduced cortical $\beta I I$ spectrin (Figs. 2, 3 and Supplementary Fig. 6b, c). Therefore, abLIM1 might be similarly recruited to and function in the spectrin network (Fig. 7e). Furthermore, it can also assemble an additional set of dense cortical F-actin networks peculiar to the non-erythroid cells (Figs. 5a, d and 7e $)^{10,13}$.

The dense intricate cortical actin networks are organized by abLIM1 and probably other actin crosslinker $(\mathrm{s})^{43}$ as well (Fig. 7e). abLIM1 was not detected on the thick cortical actin bundles at endogenous or low exogenous levels unless being highly expressed (Fig. 1 and Supplementary Fig. 2e). Furthermore, depletion of abLIM1 impaired the hierarchically branching actin networks but augmented the thick actin bundles (Fig. 5). These observations suggest that such thick bundles are assembled by unidentified actin crosslinker(s) and integrated into the abLIM1-induced actin network (Fig. 7e). This also explains why the overall cortical actin thickness was not reduced after the depletion of abLIM1 (Supplementary Fig. 5). mDia1 and the Arp2/3 complex have been shown to control the nucleation of approximately $50 \%$ of the cage-like cortical actin meshwork formed under the bleb membrane and are also important for the "conventional" cortical actin $^{42,51}$. As they respectively nucleate linear and branched actin filaments ${ }^{52}$, abLIM1 and other actin crosslinker(s) may further organize these actin filaments into complicated cortical actin networks (Figs. 5a, d and $7 \mathrm{e})^{13}$. Therefore, the relative levels or activities of these cortical actin regulators may determine both the overall and regional structural characteristics of the cell cortex and consequently modulate its functions in accordance to different cellular activities.

Interestingly, there are multiple isoforms of human abLIM1. Roof et al. report three isoforms identified from a human retina cDNA library, the full-length protein of 778 amino acid residues termed abLIM-I, an intermediate form containing three LIM motifs (abLIM-m), and a short one lacking any LIM domain (abLIM-s) ${ }^{17}$. Their PCR assays suggest that abLIM-I is only expressed in a portion of tissues such as retina, whereas abLIM-s is widely expressed $^{17}$. The full-length cDNA that we cloned from RPE1 cells encoded 743 amino acids (Supplementary Fig. 1), lacking 35 amino acid residues in the dematinhomologous region. However, our exogenous full-length abLIM1 with either Flag-, Flag-HA- or Myc-tag migrated above the $100-\mathrm{kDa}$ marker in SDS-PAGE, whereas the major band of endogenous abLIM1 in RPE1 or U2OS cells 
migrated between the 70-kDa and 100-kDa markers (see Figs. $1 \mathrm{a}, 2 \mathrm{~g}, \mathrm{~h}$ and $7 \mathrm{~b}$ for comparisons) ${ }^{23}$. As Flag- $\Delta$ LIM migrated between the 55 and $70 \mathrm{kDa}$ markers (Fig. 7b), we suspect that the major isoform expressed in RPE1 and $\mathrm{U} 2 \mathrm{OS}$ cells is the one similar to abLIM-m. This isoform is also the major one expressed in IMCD3 and NIH3T3 cells and the brain tissue, whereas HEK293T and HeLa cells appeared to also express the full-length abLIM1 (Fig. 1a). Our co-IP results suggest that the LIM-containing region of abLIM1 is inhibitory to the associations with spectrins and adducin (Fig. 7b). Its detailed roles, as well as the functional difference of the aforementioned isoforms thus remain to be clarified.

\section{Materials and methods}

\section{Plasmids and oligonucleotides}

The full-length abLIM1 and abLIM3 cDNAs (GenBank accession number MF597763, NM_001345859) were cloned from RPE1 cells ${ }^{23}$. Deletion mutants of abLIM1 were generated by PCR. The RNAi-resistant abLIM1 (abLIM1R) cDNA was created by making point mutations that did not affect the coding amino acids in the abL1-i1 target site. Vectors pEGFP-C, pFlag-CMV-2, and pET28a were used to express GFP-tagged, Flag-tagged, and Histagged proteins, respectively. The lentiviral constructs of GFP-F and RFP-Utrch ${ }^{30,} 32$ were constructed by replacing the GFP cassette of pLV-GFP-C1 with the coding sequence of GFP-F and RFP-Utrch, respectively. Lentiviral vector pFUGW (which contains IRES-EGFP as an expression marker) was used to express Flag-HA-tagged abLIM1R and luciferase for rescue experiments. All the constructs were verified by sequencing. The siRNAs were ordered from GenePharma and their sequences were described previously ${ }^{23}$.

\section{Antibodies}

Primary antibodies against the following proteins or peptides were used: $\alpha$-tubulin (Sigma T5168, mouse, 1:5000), $\beta$-actin (Sigma A5316, mouse, 1:5,000), Flag-M2 (Sigma F3165, mouse, 1:5,000; Sigma F7425, rabbit, 1:5,000), BII spectrin (BD 612563, mouse, 1:10,000 for immunoblotting and 1:40,000 for immunostaining), $\alpha \mathrm{II}$ spectrin (BD 612560, mouse, 1:2,000), $\alpha$ adducin (Santa Cruz sc-25731, rabbit, 1:2,000), GAPDH (Proteintech 10494-1-AP, rabbit, 1:10,000), GFP (Santa Cruz sc-8334, rabbit, 1:3,000), ERMs (CST 3142, rabbit, 1:1,000), phospho-ERMs (CST 3726, rabbit, 1:1,000), MLC2 (CST 3672, Rabbit, 1:500), phospho-MLC2(Ser19) (CST 3675, mouse, 1:1,000), phospho-MLC2(Thr18/Ser19) (CST 3674, rabbit, 1:1,000), and abLIM1 (home-made, rabbit, 1:5,000 for immunoblotting and 1:500-2,000 for immunostaining). Secondary antibodies conjugated with Alexa Fluor-488, -546, -647 (1:1,000) or horse radish peroxidase $(1: 5,000)$ were purchased from Invitrogen.

\section{Cell culture, transfection, and virus infection}

hTERT-RPE1 cells were maintained in Dulbecco's Modified Eagle Medium:Nutrient Mixture F-12 (DMEM/ F12) media (ThermoFisher) supplemented with $10 \%$ fetal bovine serum (FBS), 100 units $/ \mathrm{ml}$ penicillin, $100 \mu \mathrm{g} / \mathrm{ml}$ streptomycin, and $10 \mu \mathrm{g} / \mathrm{ml}$ Hygromycin B (Invitrogen). HEK293T and U2OS cells were maintained in DMEM supplemented with the same amount of FBS, penicillin, and streptomycin. For plasmid transfection, the conventional calcium phosphate method was used for HEK293T cells and Lipofectamine 2000 (Invitrogen) for RPE1 and U2OS cells. Lipofectamine RNAiMAX (Invitrogen) was used for siRNA transfection. Lentiviral particles were packaged as described previously ${ }^{53}$. The virusinfected RPE1 cells were isolated by FACS based on expressed fluorescent marker(s) and cultured as stable cells. In this study, HEK293T cells were mainly used for biochemical assays due to their high transfection efficiency for plasmids.

\section{Light microscopy}

For immunofluorescent microscopy, RPE1 or U2OS cells were cultured on coverslips and fixed with $4 \%$ paraformaldehyde in PBS for $15 \mathrm{~min}$ at room temperature. To induce a spherical morphology, the cells were partially detached from the substratum by treating with $0.5 \mathrm{mM}$ EDTA in PBS for $10 \mathrm{~min}$ at $37^{\circ} \mathrm{C}$ prior to the fixation. For immunostaining concerning abLIM1, the cells were preextracted with $0.1 \%$ Triton X-100 in PBS for $30-60 \mathrm{sec}$ prior to the fixation. The fixed cells were permeabilized with $0.5 \%$ Triton X-100 in PBS for 10 min and blocked with $4 \%$ BSA in TBST for $1 \mathrm{~h}$. The incubation with primary and secondary antibodies was carried out at $4{ }^{\circ} \mathrm{C}$ overnight and at room temperature for $1 \mathrm{~h}$. PhalloidinTRITC (Sigma, P1951, 1:1,000) or phalloidin-Alexa Fluor647 (Invitrogen, A22287, 1:1,000) was used to stain Factin. Nuclear DNA was stained with 4, 6-diamidino-2phenylindole (DAPI). Optical sections were captured at 0.3- $\mu \mathrm{m}$ intervals using a confocal microscope (TCS SP8, Leica). The resulting z-stack images were rendered $2 \mathrm{D}$ by maximum intensity projections unless otherwise stated.

For time-lapse microscopy, RPE1 cells were maintained in L-15 medium (Invitrogen) supplemented with $10 \%$ fetal bovine serum, 100 units $/ \mathrm{ml}$ penicillin, and $100 \mu \mathrm{g} / \mathrm{ml}$ streptomycin. Image sequences for cell migration or spreading were collected at 6 -min intervals for $10 \mathrm{~h}$ using a CCD camera (Evolution QEi, Media Cybernetics) on an Olympus IX81 microscope equipped with a motorized stage and a $37^{\circ} \mathrm{C}$ heating chamber. Blebbing dynamics was traced with a spinning disc microscope (UltraVIEW VoX, PerkinElmer) at 10-sec intervals for $30 \mathrm{~min}$.

STED images of abLIM1 (Alexa Fluor-546) and F-actin (Alexa Fluor-647) were acquired on a Leica TCS SP8 STED $\times 3$ microscope with $660 \mathrm{~nm}$ and pulsed $775 \mathrm{~nm}$ 
lasers for depletion, $546 \mathrm{~nm}$ and $647 \mathrm{~nm}$ of a pulsed white light laser (WLL) for excitation, respectively. The gating time for both STED channels ranged from $0.5 \mathrm{~ns}$ to $6 \mathrm{~ns}$. A Leica HC PL APO CS2 $\times 100 / 1.40$ oil objective was used.

\section{Scanning electron microscopy}

For imaging cell surface, RPE1 cells grown on glass coverslips were fixed for $1.5 \mathrm{~h}$ or overnight at $4{ }^{\circ} \mathrm{C}$ with $2.5 \%$ glutaraldehyde in PBS, followed by three rounds of wash (20 min each) with PBS and then a post-fixation in $1 \%$ osmic acid for $1 \mathrm{~h}$. After three times of wash $(10 \mathrm{~min}$ each), the samples were dehydrated by exposure to serial ethanol dilutions and dried in a critical point dryer. They were coated with 10-nm to15-nm platinum and imaged with a scanning EM (FEI Quanta 250).

For imaging cortical actin, RPE1 cells were processed as described $^{38}$ with minor modifications. Briefly, the cells cultured on glass coverslips were washed quickly with PBS pre-warmed to $37^{\circ} \mathrm{C}$ and transferred to PEM buffer (100 mM PIPES ( $\mathrm{pH}$ 6.9), $1 \mathrm{mM}$ EGTA, and $1 \mathrm{mM} \mathrm{MgCl}_{2}$ ) containing 1\% Triton X-100 for 5 min. After two rounds of wash in PEM buffer, the cells were fixed in PEM buffer containing $2 \%$ glutaraldehyde for $20 \mathrm{~min}$. The cells were then dehydrated by exposure to serial ethanol dilutions, dried in a critical point dryer, and coated with 5 to $7-\mathrm{nm}$ platinum prior to imaging.

\section{Atomic force microscopy}

Imaging and cell elasticity measurements were performed using a Bioscope Resolve atomic force microscope (Bruker, Santa Barbra, CA), operating in the PeakForce live cell mode in DMEM at room temperature. Olympus AC40-TS cantilevers (tip length $40 \mu \mathrm{m}$, tip radius $10 \mathrm{~nm}$, nominal spring constant $0.09 \mathrm{~N} / \mathrm{m}$ ) were used in all experiments. Before each measurement, we performed a force-versus-distance curve on the petri dish adjacent to the cells to measure the detection sensitivity and determined the spring constant of the cantilever by recording the thermal noise power spectrum in liquid. For all measurements, the scan rate was $0.3 \mathrm{~Hz}$ and $0.4 \mathrm{~Hz}$ for whole cell and high resolution imaging of the cortex, respectively, with a frame of $128 \times 128$ pixels, using a PeakForce frequency of $1 \mathrm{kHz}$ and an oscillation amplitude of $100 \mathrm{~nm}$. The force setpoint was set to $150 \mathrm{pN}$ and an automatic gain control was used to minimize the PeakForce error. Image analysis was performed using the Nanoscope analysis v1.80 (Bruker Nano Surfaces, Santa Barbara).

\section{Protein expression and purification}

Expressions of His-GFP-tagged proteins in E. coli were induced with $0.2 \mathrm{mM}$ IPTG at $16^{\circ} \mathrm{C}$ for $20 \mathrm{~h}$. Protein purification was performed at $4{ }^{\circ} \mathrm{C}$ according to manufacturer's protocol (Qiagen, Sigma). Briefly, E. coli was lysed in the lysis buffer [ $20 \mathrm{mM}$ Tris- $\mathrm{HCl}(\mathrm{pH} 8.0), 300$ $\mathrm{mM} \mathrm{NaCl}, 5 \%$ glycerol, $5 \mathrm{mM}$ imidazole, $1 \%$ TritonX-100, $1 \mathrm{mM}$ phenylmethylsulfonyl fluoride (PMSF), and protease inhibitor cocktail (Calbiochem)] using high pressure homogenizer (JNBIO JN-02C). After centrifugation to remove debris, the lysates were incubated with Ni-NTA beads (Qiagen) for $2 \mathrm{~h}$. Then the beads were washed with wash buffer ( $20 \mathrm{mM}$ Tris- $\mathrm{HCl}$ (pH 8.0), $300 \mathrm{mM} \mathrm{NaCl}, 5 \%$ glycerol, $20-70 \mathrm{mM}$ imidazole) for $50-75 \times$ beads volumes and eluted with elution buffer $(20 \mathrm{mM}$ Tris- $\mathrm{HCl}$ $(\mathrm{pH} \quad 8.0), \quad 300 \mathrm{mM} \mathrm{NaCl}, \quad 5 \%$ glycerol, $300 \mathrm{mM}$ imidazole). The eluted proteins were dialyzed twice with large volumes of PBS for $1 \mathrm{~h}$ each, followed by concentration using spin columns (Amicon 10-kDa ultra centrifugal filters, Millipore) following manufacturer's protocol. For proteins susceptible to precipitation during the dialysis, we slowed down the process by capping them in Eppendorf tubes with $14-\mathrm{kDa}$ dialysis membrane, followed by dialyzing in PBS twice for approximately $10 \mathrm{~h}$ each. His-abLIM1 and -abLIM3 were purified as inclusion bodies, solubilized in $8 \mathrm{M}$ urea, and dialyzed. The purified proteins were divided into 5 - or $10-\mu \mathrm{l}$ aliquots, snap frozen in liquid nitrogen, and stored at $-80^{\circ} \mathrm{C}$.

\section{F-actin bundling assays}

Non-muscle actin $(1 \mathrm{mg} / \mathrm{ml}$; Cytoskeleton Inc.) in $5 \mathrm{mM}$ Tris- $\mathrm{HCl}(\mathrm{pH} 7.5), 0.2 \mathrm{mM} \mathrm{CaCl}_{2}$, and $0.2 \mathrm{mM}$ ATP was mixed with 0.1 volume of $10 \times$ polymerization buffer [100 $\mathrm{mM}$ Tris- $\mathrm{HCl}$ (pH 7.5), $500 \mathrm{mM} \mathrm{KCl}, 20 \mathrm{mM} \mathrm{MgCl}_{2}$, and $10 \mathrm{mM}$ ATP] and incubated at $25^{\circ} \mathrm{C}$ for $1 \mathrm{~h}$ to polymerize F-actin. $6 \mu \mathrm{l}$ of the F-actin-containing solution (containing $22 \mu \mathrm{m}$ actin) were then mixed with $16 \mu \mathrm{l}$ of different concentrations of His-GFP-tagged proteins and incubated at $25^{\circ} \mathrm{C}$ for $1 \mathrm{~h}$. An aliquot of each mixture was stained with phalloidin-TRITC $(0.001 \mu \mathrm{g} / \mu \mathrm{l}$ final concentration; Sigma-Aldrich) for $15 \mathrm{~min}$ at $25^{\circ} \mathrm{C}$ and mounted into a $35-\mathrm{mm}$ Petri dish with cover glass bottom for confocal microscopy. The remaining aliquot of the mixture was loaded onto carbon-coated and glow-discharged copper grids (SPI Supplies) for $1 \mathrm{~min}$, washed once with 0.75\% uranyl formate, and stained with $0.75 \%$ uranyl formate for $60 \mathrm{~s}$. Then the sample was air-dried and imaged in a transmission electron microscope (FEI Tecnai G2 Spirit) operated at $120 \mathrm{kV}$.

\section{Co-immunoprecipitation}

Cells cultured in a 10-cm Petri dish were lysed on ice in $1 \mathrm{ml}$ of lysis buffer [20 mM Tris- $\mathrm{Cl}$ ( $\mathrm{pH} 7.5), 100 \mathrm{mM} \mathrm{KCl}$, $0.1 \%$ NP-40, 1 mM EDTA, $10 \%$ glycerol, $10 \mathrm{mM} \mathrm{Na}_{4} \mathrm{P}_{2} \mathrm{O}_{7}$, $1 \mathrm{mM} \mathrm{Na} \mathrm{VO}_{4}, 50 \mathrm{mM} \mathrm{NaF}, 1 \mathrm{mM}$ phenylmethylsulfonyl fluoride, $1 \mathrm{mM}$ DTT, and protease inhibitor cocktail (Calbiochem)]. The lysates were pre-cleared by centrifugation at $14,000 \times g$ for $10 \mathrm{~min}$. The supernatants were 
mixed with $20 \mu \mathrm{l} 50 \%$ slurry of anti-Flag M2 resin (Sigma) or anti-GFP resin (Chromotek) and incubated at $4{ }^{\circ} \mathrm{C}$ for $2 \mathrm{~h}$ in a rotary station. After three times of wash with the lysis buffer and then with wash buffer $[20 \mathrm{mM}$ Tris-Cl (pH 7.5), $150 \mathrm{mM} \mathrm{KCl}, 0.5 \%$ NP-40, $1 \mathrm{mM}$ EDTA, 10\% glycerol, $10 \mathrm{mM} \mathrm{Na}_{4} \mathrm{P}_{2} \mathrm{O}_{7}, 1 \mathrm{mM} \mathrm{Na}_{3} \mathrm{VO}_{4}, 50 \mathrm{mM} \mathrm{NaF}, 1$ $\mathrm{mM}$ phenylmethylsulfonyl fluoride, and $1 \mathrm{mM}$ DTT], proteins on the anti-Flag beads were eluted using $30 \mu \mathrm{l}$ of $1 \mathrm{mg} / \mathrm{ml}$ Flag peptide, whereas those on the anti-GFP beads were solubilized using SDS loading buffer. To prepare samples for shotgun mass spectrometry, lysates from HEK293T cells transfected for $48 \mathrm{~h}$ to express Flagtagged abLIM1 or luciferase were mixed with P0 mouse brain lysates and subjected to co-IP as described previously ${ }^{41}$.

\section{Quantification and statistical analysis}

Tracks of the nucleus over $600 \mathrm{~min}$, generated using ImageJ software $(\mathrm{NIH})$, were used as trajectories of migrating cells. The length of the straight line between the initial $(0 \mathrm{~min})$ and end $(600 \mathrm{~min})$ positions of a trajectory was measured using ImageJ as the net displacement of the cell.

To determine the Young's modulus of the cells with AFM, we employed the Dejarguin, Muller, Toporov (DMT) model ${ }^{54}$ using the equation,

$F=\frac{4 E}{3\left(1-v^{2}\right)} \sqrt{R} d^{\frac{3}{2}}+F_{a d h}$ where $F$ is the force applied, $F_{\text {adh }}$ is the adhesion force measured from the force curve, $E$ is the Young's modulus, $R$ is the tip radius, $d$ is the indentation depth, and $v$ is the Poisson ratio $(0.5)^{55,56} . F_{\text {adh }}$ was measured during PeakForce imaging. For all measurements, we examined individual approximately $10 \times 10-\mu \mathrm{m}^{2}$ regions isolated from the whole cell data. For the regions away from the nucleus, we limited our examinations to those sufficiently far from the cell boundary to avoid contributions of the underlying substrate to the elasticity measurements in the thinner regions of the cell.

To measure cell cortex thickness, STED images of single optical section at approximately the equatorial position of U2OS cells were used. Three separate fluorescence intensity line scans were performed across the border of a cell at where the cortex staining was relatively uniform (see Supplementary Fig. 5b). Average width of the intensity curves at the $50 \%$ position of the intensity peak was used as the cortex thickness of the cell.

Unpaired Student's $t$-test was performed for statistical analysis by using SigmaPlot (Systat Software, Inc.). Differences were considered significant when $P<0.05$.

\section{Data availability}

Data supporting the reported results are available upon request to X.Z.

\section{Acknowledgements}

The authors thank Drs. Xiumin Yan and Yixian Zheng for stimulating discussions, the institutional Core Facility for Cell Analysis, National Center for Protein Science Shanghai, and Yongfeng Zhou for technical supports. This work was equally supported by National Natural Science Foundation of China (31330045), National Key R\&D Program of China (2017YFA0503500), and Chinese Academy of Sciences (XDB19020102). It was also supported by NSFC grants 11374207 (Z.S.), 81627801 (Z.S.), 31370750 (D.M.C.), 31670722 (D.M.C.), and 91129000 (X.Z. and Z.S.).

\section{Author details}

${ }^{1}$ State Key Laboratory of Cell Biology, CAS Center for Excellence in Molecular Cell Science, Shanghai Institute of Biochemistry and Cell Biology, Chinese Academy of Sciences, University of Chinese Academy of Sciences, 320 Yueyang Road, Shanghai 200031, China. ${ }^{2}$ Shanghai Center for Systems Biomedicine, Key Laboratory of Systems Biomedicine (Ministry of Education), Shanghai Jiao Tong University, 800 Dongchuan Road, Shanghai 200240, China. ${ }^{3}$ Bio-ID Center, School of Biomedical Engineering, Shanghai Jiao Tong University, 800 Dongchuan Road, Shanghai 200240, China

\section{Authors contributions}

X.Z. conceived and directed the project; G.L. and S.H. performed major experiments; S.Y. performed in vitro actin binding assays and examined subcellular localizations of some mutants; J.W. performed AFM and analyzed cell stiffness; D.M.C. and Z.S supervised the AFM experiments; J.C. constructed and validated GFP-UtrCH; X.Z. and G.L. designed experiments, interpreted data, and wrote the paper.

\section{Conflict of interest}

The authors declare that they have no conflict of interest.

Supplementary Information accompanies the paper at (https://doi.org/ 10.1038/s41421-018-0040-3).

Received: 9 January 2018 Revised: 4 May 2018 Accepted: 8 May 2018 Published online: 24 July 2018

\section{References}

1. Salbreux, G., Charras, G. \& Paluch, E. Actin cortex mechanics and cellular morphogenesis. Trends Cell Biol. 22, 536-545 (2012).

2. Andrade, D. M. et al. Cortical actin networks induce spatio-temporal confinement of phospholipids in the plasma membrane--a minimally invasive investigation by STED-FCS. Sci. Rep. 5, 11454 (2015).

3. Koster, D. V. \& Mayor, S. Cortical actin and the plasma membrane: inextricably intertwined. Curr. Opin. Cell Biol. 38, 81-89 (2016).

4. Charras, G. \& Paluch, E. Blebs lead the way: how to migrate without lamellipodia. Nat. Rev. Mol. Cell Biol. 9, 730-736 (2008).

5. Machnicka, B., Grochowalska, R., Boguslawska, D. M., Sikorski, A. F. \& Lecomte, M. C. Spectrin-based skeleton as an actor in cell signaling. Cell Mol. Life Sci. 69, 191-201 (2012).

6. Wu, S. K. et al. Cortical F-actin stabilization generates apical-lateral patterns of junctional contractility that integrate cells into epithelia. Nat. Cell Biol. 16, 167-178 (2014).

7. Baines, A. J. The spectrin-ankyrin-4.1-adducin membrane skeleton: adapting eukaryotic cells to the demands of animal life. Protoplasma 244, 99-131 (2010).

8. Fritzsche, M. et al. Cytoskeletal actin dynamics shape a ramifying actin network underpinning immunological synapse formation. Sci. Adv. 3, e1603032 (2017).

9. Bennett, V. \& Baines, A. J. Spectrin and ankyrin-based pathways: metazoan inventions for integrating cells into tissues. Physiol. Rev. 81, 1353-1392 (2001).

10. Fritzsche, M., Lewalle, A., Duke, T., Kruse, K. \& Charras, G. Analysis of turnover dynamics of the submembranous actin cortex. Mol. Biol. Cell 24, 757-767 (2013).

11. Ridley, A. J. Life at the leading edge. Cell 145, 1012-1022 (2011).

12. Charras, G. T., Hu, C. K., Coughlin, M. \& Mitchison, T. J. Reassembly of contractile actin cortex in cell blebs. J. Cell Biol. 175, 477-490 (2006). 
13. Li, D. et al. ADVANCED IMAGING. Extended-resolution structured illumination imaging of endocytic and cytoskeletal dynamics. Science 349, aab3500 (2015).

14. Xu, K., Zhong, G. \& Zhuang, X. Actin, spectrin, and associated proteins form a periodic cytoskeletal structure in axons. Science 339, 452-456 (2013).

15. D'Este, E., Kamin, D., Gottfert, F., El-Hady, A. \& Hell, S. W. STED nanoscopy reveals the ubiquity of subcortical cytoskeleton periodicity in living neurons. Cell Rep. 10, 1246-1251 (2015).

16. Sidenstein, S. C. et al. Multicolour multilevel STED nanoscopy of actin/spectrin organization at synapses. Sci. Rep. 6, 26725 (2016).

17. Roof, D. J., Hayes, A., Adamian, M., Chishti, A. H. \& Li, T. Molecular characterization of abLIM, a novel actin-binding and double zinc finger protein. J. Cell Biol. 138, 575-588 (1997).

18. Rana, A. P., Ruff, P., Maalouf, G. J., Speicher, D. W. \& Chishti, A. H. Cloning of human erythroid dematin reveals another member of the villin family. Proc. Natl Acad. Sci. USA 90, 6651-6655 (1993).

19. Azim, A. C., Knoll, J. H., Beggs, A. H. \& Chishti, A. H. Isoform cloning, actin binding, and chromosomal localization of human erythroid dematin, a member of the villin superfamily. J. Biol. Chem. 270, 17407-17413 (1995).

20. Barrientos, T. et al. Two novel members of the ABLIM protein family, ABLIM-2 and -3 , associate with STARS and directly bind F-actin. J. Biol. Chem. 282, 8393-8403 (2007)

21. Krupp, M., Weinmann, A., Galle, P. R. \& Teufel, A. Actin binding LIM protein 3 (abLIM3). Int J. Mol. Med. 17, 129-133 (2006).

22. Frank, D. \& Frey, N. Cardiac Z-disc signaling network. J. Biol. Chem. 286, 9897-9904 (2011)

23. Cao, J. et al. miR-129-3p controls cilia assembly by regulating CP110 and actin dynamics. Nat. Cell Biol. 14, 697-706 (2012).

24. Schneider, P. et al. Identification of a novel actin-dependent signal transducing module allows for the targeted degradation of GLI1. Nat. Commun. 6, 8023 (2015).

25. Schneider, P. et al. Corrigendum: identification of a novel actin-dependent signal transducing module allows for the targeted degradation of GLI1. Nat. Commun. 6, 8741 (2015)

26. Shan, Y. et al. Nudel and FAK as antagonizing strength modulators of nascent adhesions through paxillin. PLoS Biol. 7, e1000116 (2009).

27. Mitra, S. K., Hanson, D. A. \& Schlaepfer, D. D. Focal adhesion kinase: in command and control of cell motility. Nat. Rev. Mol. Cell Biol. 6, 56-68 (2005).

28. Charras, G. T. A short history of blebbing. J. Microsc. 231, 466-478 (2008).

29. Tinevez, J. Y. et al. Role of cortical tension in bleb growth. Proc. Natl Acad. Sci. USA 106, 18581-18586 (2009).

30. Jiang, W. \& Hunter, T. Analysis of cell-cycle profiles in transfected cells using a membrane-targeted GFP. Biotechniques 24, 349-350 (1998). 352, 354.

31. Liang, Y. et al. Nudel functions in membrane traffic mainly through association with Lis1 and cytoplasmic dynein. J. Cell Biol. 164, 557-566 (2004).

32. Burkel, B. M., von Dassow, G. \& Bement, W. M. Versatile fluorescent probes for actin filaments based on the actin-binding domain of utrophin. Cell Motil. Cytoskel. 64, 822-832 (2007).

33. Bergert, M., Chandradoss, S. D., Desai, R. A. \& Paluch, E. Cell mechanics control rapid transitions between blebs and lamellipodia during migration. Proc. Natl Acad. Sci. USA 109, 14434-14439 (2012).

34. Straight, A. F. et al. Dissecting temporal and spatial control of cytokinesis with a myosin II Inhibitor. Science 299, 1743-1747 (2003).

35. Watanabe, T., Hosoya, H. \& Yonemura, S. Regulation of myosin II dynamics by phosphorylation and dephosphorylation of its light chain in epithelial cells. Mol. Biol. Cell 18, 605-616 (2007).
36. Sakurada, K., Seto, M. \& Sasaki, Y. Dynamics of myosin light chain phosphorylation at Ser19 and Thr18/Ser19 in smooth muscle cells in culture. Am. J. Physiol. 274, C1563-C1572 (1998).

37. Fehon, R. G., McClatchey, A. I. \& Bretscher, A. Organizing the cell cortex: the role of ERM proteins. Nat. Rev. Mol. Cell Biol. 11, 276-287 (2010).

38. Svitkina, T. Electron microscopic analysis of the leading edge in migrating cells. Methods Cell Biol. 79, 295-319 (2007).

39. Zhang, Y. et al. In vivo dynamics of the cortical actin network revealed by fastscanning atomic force microscopy. Microscopy 66, 1-11 (2017).

40. Vicidomini, G. et al. Sharper low-power STED nanoscopy by time gating. Nat. Meth. 8, 571-573 (2011).

41. Shen, $Y$. et al. Nudel binds Cdc42GAP to modulate Cdc42 activity at the leading edge of migrating cells. Dev. Cell 14, 342-353 (2008).

42. Bovellan, M. et al. Cellular control of cortical actin nucleation. Curr. Biol. 24 1628-1635 (2014)

43. Revenu, C., Athman, R., Robine, S. \& Louvard, D. The co-workers of actin filaments: from cell structures to signals. Nat. Rev. Mol. Cell Biol. 5, 635-646 (2004).

44. Chhabra, E. S. \& Higgs, H. N. The many faces of actin: matching assembly factors with cellular structures. Nat. Cell Biol. 9, 1110-1121 (2007)

45. Chen, L., Jiang, Z. G., Khan, A. A., Chishti, A. H. \& McKnight, C. J. Dematin exhibits a natively unfolded core domain and an independently folded headpiece domain. Protein Sci. 18, 629-636 (2009).

46. Chen, L., Brown, J. W., Mok, Y. F., Hatters, D. M. \& McKnight, C. J. The allosteric mechanism induced by protein kinase $A$ (PKA) phosphorylation of dematin (band 4.9). J. Biol. Chem. 288, 8313-8320 (2013).

47. Vardar, D. et al. Villin-type headpiece domains show a wide range of F-actinbinding affinities. Cell Motil. Cytoskel. 52, 9-21 (2002).

48. Husain-Chishti, A., Levin, A. \& Branton, D. Abolition of actin-bundling by phosphorylation of human erythrocyte protein 4.9. Nature 334, 718-721 (1988).

49. Koshino, I., Mohandas, N. \& Takakuwa, Y. Identification of a novel role for dematin in regulating red cell membrane function by modulating spectrinactin interaction. J. Biol. Chem. 287, 35244-35250 (2012).

50. Lu, Y. et al. Gene disruption of dematin causes precipitous loss of erythrocyte membrane stability and severe hemolytic anemia. Blood $\mathbf{1 2 8}$, 93-103 (2016).

51. Fritzsche, M., Erlenkamper, C., Moeendarbary, E., Charras, G. \& Kruse, K. Actin kinetics shapes cortical network structure and mechanics. Sci. Adv. 2, e1501337 (2016).

52. Campellone, K. G. \& Welch, M. D. A nucleator arms race: cellular control of actin assembly. Nat. Rev. Mol. Cell Biol. 11, 237-251 (2010).

53. Zhao, $\mathrm{H}$. et al. The Cep63 paralogue Deup1 enables massive de novo centriole biogenesis for vertebrate multiciliogenesis. Nat. Cell Biol. 15 1434-1444 (2013).

54. Boer-Duchemin, E., Tranvouez, E. \& Dujardin, G. The interaction of an atomic force microscope tip with a nano-object: a model for determining the lateral force. Nanotechnology 21, 455704 (2010).

55. Eghiaian, F., Rigato, A. \& Scheuring, S. Structural, mechanical, and dynamical variability of the actin cortex in living cells. Biophys. J. 108 1330-1340 (2015).

56. Trickey, W. R., Baaijens, F. P., Laursen, T. A., Alexopoulos, L. G. \& Guilak, F. Determination of the Poisson's ratio of the cell: recovery properties of chondrocytes after release from complete micropipette aspiration. J. Biomech. 39 78-87 (2006). 